the best British wheat varieties against their parents and established an average increase in the hybrids of 10 per cent in number of ears per plant and $4 \cdot 6$ per cent in weight of grain per ear, a total increase of 15 per cent in yield of grain. Some individual crosses would naturally show more heterosis than others, so that this strongly suggested that wheat could be bred for British conditions with yield increases of 20 per cent at least.

Dr. J. S. Huxley and others stressed the need for physiological and genetical examination of practical breeders' data, which are now available.

Prof. J. B. S. Haldane pointed out the importance of natural selection in domestic plants and animals and of undesirable selection for high seed number, or for longevity; the fallacy of assuming that inbreeding necessarily leads to homozygosis; and the danger of standardized clonal reproduction leading to epidemics.

Mr. W. J. C. Lawrence said that ultimate progress in plant breeding would often depend on the selection for efficiency of specific nutrient intake, for rich soils as well as for poor unbalanced ones. In this regard Dr. G. D. H. Bell discussed the need for combined manurial and variety trials for selection under local and good conditions.

Dr. F. Yates directed attention to the importance of testing new varieties of agricultural crops under a wide range of environmental conditions. Varieties might vary considerably in their reactions to different weather conditions, different soil types and different nutrient supplies in the shape of fertilizers. Thus, for example, one of the biggest factors limiting the yield of cereals in Great Britain is their inability to stand up to high levels of nitrogenous manuring without lodging. Modern developments in the technique of experimental design, in particular the development of factorial experiments, which enable several factors to be tested simultaneously (for example, varieties and different fertilizer components), provided the necessary machinery by which such tests can be efficiently made. It is equally important to carry out the tests at a number of different centres and over a number of years, so as to obtain adequate variation in weather and soil conditions. Any experimental programme of this type nocessarily involves a large number of co-ordinated experiments. The organization required for the efficient execution of such experiments has not yet been fully developed, but there is now good prospect of radical improvement in this respect. It is of the utmost importance that the plant-breeding interests should be adequately represented, and should lend their full support to the development of such a co-ordinated programme.

Dr. Darlington, summing up, said that the papers showed an important contrast in treatment between two levels of breeding practice. On one hand there is the situation where common sense alone will sufficiently indicate the breeding programme in its initial stages. This is particularly true in undeveloped conditions and those where negative selection has been practised. Examples have been described in grasses and forest trees where commercial practice favours quantity of seed rather than quality of fodder or timber, and in cattle-breeding when the breed society, founded to improve cattle, has become organized to prevent improvement, a condition which will obviously be broken down by the spread of artificial insemination. No more economical or fruitful programme of genetical research in cattle-breeding could be suggested than the long-neglected survey of actual breeding practice and performance in Great Britain to-day, the outlines of which were indicated by several speakers. At the other extreme is the situation of the highly developed breeds of poultry and varieties of cereals where maintenance and, still more, improvement demand a skilful combination of elaborate techniques. The statistician is necessary for design and for interpretation, the cytologist for exploration and creation, the geneticist for planning and direction. The discussion was chiefly useful in showing what the different levels of organization are and where each is required.

\section{TUBERCULOSIS AND PULMONARY DISEASE}

A RECENT issue of the British Medical Bulletin (2, No. $2 ; 1944)$ is devoted to pulmonary disease. It also contains two new features: one consists of notes from medical publications which are not classified as journals and the other lists the titles and authors of papers in medical journals published in Great Britain and Northern Ireland.

Dr. P. M. D'Arcy Hart, in a special article on the medical and social aspects of pulmonary disease, deals with tuberculosis and industrial diseases of the lungs. The Committee on Tubereulosis in War-time, set up by the Medical Research Council, reported that the social background of tuberculosis is of primary importance and emphasizes the part played by war-time conditions in the rise of mortality due to tuberculosis which has occurred between 1939 and 1941. Blackout, over-crowding, the movement of populations, destruction of homes by bombing, and the entry into industry of people who are not accustomed to its conditions and fatigue are all factors contributing to this rise. Nutritional deficiency is probably less important in this War than it was during 1914-18, because of our efficient national food policy. But working conditions should be carefully watched, especially those of young adults, who are especially susceptible to tuberculosis. The Committee recommends (1) routine mass radiography and advocates the miniature method pioneered by Abreu in Brazil, priority being given to young adults such as factory employees, medical students, nurses, merchant seamen; (2) special money grants to sufferers for at least a year to enable them to leave work, maintain their own standard of living and that of their families and to undergo treatment; (3) rehabilitation of convalescents and, if possible, their gradual return to work.

The Ministry of Health has already instituted the main recommendations of this report. War-time restrictions, Dr. Hart says, have limited the manufacture and issue of miniature radiography sets, but about half a dozen local authorities have received and are using them, and field trials are being carried out with them by a team appointed by the Medical Research Council. It is hard to understand why the manufacture of these sets should not be a first priority. The Ministry of Health's scheme of financial help is in general operation already. The general policy is one of continued watchfulness and avoidance of complacency which everyone will commend.

The Medical Research Council Committee on 
Industrial Pulmonary Disease has studied the problem of silicosis in South Wales miners and also the environment of these workers. Dr. D'Arcy Hart summarizes the resultant additions to our knowledge of this problem and the Committee's recommendations. Readers interested in other work being done to increase the safety of the mines will find useful the Ministry of Fuel and Power's annual report for 1942 of the Safety in Mines Research Board (London : H.M. Stationery Oifice, 1943. 1s. net), which deals with work on coal-dust and fire-damp explosions, mining explosives, falls of ground, electrical researches and kindred problems.

In the same issue of the British Medical Bulletin Mr. R. C. Brock writes a valuable article on the present position of thoracic surgery. The advances in this field in recent years have been remarkable, and the surgical treatment of tuberculosis has an important place among them. Mr. Brock names $\mathrm{X}$-rays and anæsthesia as the twin pillars of thoracic surgery, which requires of the surgeon such a wide knowledge of the anatomy and physiology of the chest as well as his essential pathological and medical experience. The anæsthetist has the especially difficult job of maintaining respiration and the circulation of the blood during operations on the very organs which maintain these essential functions. Mr. Brock thinks that, during the next ten years, we shall see advances in the surgery of the heart and cosophagus as great as those which have occurred in thoracic surgery during the past ten years. A good idea of the quality of the anatomical research on which thoracic medicine and surgery are based is given by the succeeding illustrated article on the anatomy of the bronchi by Dr. A. F. Foster-Carter. Excellent bibliographies add to the value of all these articles. They are supplemented by reviews of selected articles on pulmonary anatomy, surgery and disease, and on further papers on tuberculosis in children and on the statistical and social aspects of this outstanding scourge of our civilization.

The results of further important work on various aspects of tuberculosis have been published in The Lancet and the British Medical Journal during recent months and we know, from reports on the health of the occupied countries, how important a factor tuberculosis will be in the immense task of reconstruction after the War. A correspondent of The Lancet (Fob. 12, 1944, p. 225), taking his information from French underground medical papers, states that tuberculosis has increased in that country by at least 20-30 per cent. French medical men, moved to horror by the ever-increasing number of French workers deported to Germany who return with tuberculosis, are unable to save their lives because the necessary diets and drugs are not available. They are trying to sabotage the deportations by ordering long rest-cures, laboratory investigations, consultations with absent specialists and similar means. The discussion on nutrition in enemy-occupied Europe at the meeting of the Royal Society of Medicine on November 23, 1943 (The Lancet, Dec. 4, 1943, p. 703, and Proc. Roy. Soc. Med., 5, 37, Jan. 1944, p. 113) reveals a similar grave situation in Greece, JugoSlavia and Belgium. In the U.S.S.R. the problem is being tackled partly by village settlements similar to the English settlements at Papworth and Preston Hall, but the Russians appear to be concentrating on large-scale rehabilitation in and around the normal sites of industry (Brit. Med. J., Nov. 20, 1943, p. 652).

G. LAPAGE.

\section{SCIENCE CLASS LECTURE CINE-FILMS}

A PARAGRAPH in the News and Views column $A$ of Nature of November 27, 1943, p. 623 , referred to a ciné-film showing the Brownian movement Dr. Quintin Moore, Mr. Thos. Smith Wylie; and Mr. Frank G. Conway, of the Royal Technical College, Glasgow, have given the following particulars regarding the method and apparatus.

Microscopical Unit. Through the courtesy of the Royal Technical College, Glasgow, we had the use of a 'Siedentopf' Cardioid Ultra-microscope (manufactured by Carl Zeiss) together with associated apparatus.

The source of light was a 15-amp. carbon are with a horizontally positioned positive carbon. A converging lens projected the light as a parallel beam. The light passed through a cooling chamber containing slightly acidulated 20 per cent ferrous ammonium sulphate solution, then directly to the 'Cardioid Condenser', which was fitted into the sleeve of the Abbe illuminator of the microscope. The top of the condenser was connected to the object slide by a layer of distilled water.

A $1 \mathrm{~mm}$. thick quartz slide and quartz cover formed a chamber which was mounted in a metal holder and held firmly against the stage of the microscope. This quartz chamber resembles that of a hæmocytometer slide without engraved ruling; but the depth is considerably less, only $2-4 \mu$ deep. A colloidal solution of Carey Lea's silver, suitably diluted, was placed on the centre of the object slide and excess solution overflowed into the surrounding channel. The dimensions of the colloidal silver particles were of the order of $50 \mathrm{~m} \mu$.

By careful adjustment and focusing, the oblique light from the condenser was made to illuminate completely the thin stratum of colloidal solution in the chamber. None of this oblique light can enter the microscope directly, due to the high numerical aperture of the objective. The light which does enter is scattered from the surfaces of the colloidal particles and it passes into the following microscopical combination: an apochromatic glycerine immersion objective adapted for use with the thick quartz cover and of magnification 58, focal length $3 \mathrm{~mm}$., and numerical aperture $0 \cdot 85$. The objective, carried by a centring nosepiece, was used in conjunction with a compensated focusing eyepiece, and the combination gave a magnification of 1,160 diameters.

Photographic Unit. This consisted of a Bell-Howell $16 \mathrm{~mm}$. camera fitted with a $f 1.5$ lens of 1 inch focal length.

The camera was mounted on a heavy base and carefully set up so that the lens combinations of the microscope and camera were in accurate co-axial alignment. The camera lens set to infinity and at full aperture was placed in a ground glass focusing mount, which in turn was clamped to the eyepiece of the microscope. Through this combination the microscope was focused. The lens was then replaced in the camera, maintaining the same relative positions of lens and eyepiece.

Kodak Super XX reversal panchromatic film was used with a camera frame speed of 4 per sec., giving an exposure of approximately $\frac{1}{8}$ sec. per frame. No filters were used.

Excellent darkground effects were obtained with the above equipment provided the requisite care was 